\title{
Gastric evacuation rates in male Clearnose Skate (Leucoraja eglanteria) in the laboratory
}

\author{
Linda L. Stehlik ${ }^{1 *}$, Beth A. Phelan ${ }^{2}$, John Rosendale ${ }^{3}$, and Jonathan A. Hare ${ }^{4}$ \\ ${ }^{1,2,3}$ Northeast Fisheries Science Center \\ National Marine Fisheries Service, NOAA \\ James J. Howard Marine Sciences Laboratory \\ 74 Magruder Road \\ Highlands, New Jersey 07732 \\ 4.Northeast Fisheries Science Center \\ National Marine Fisheries Service, NOAA \\ Narragansett Laboratory \\ 28 Tarzwell Drive \\ Narragansett, RI 02882 \\ *Corresponding author: Tel.: +1 732-872-3081; Email: Linda.Stehlik@noaa.gov
}

STEHLIK L. L., B. A. PHELAN, J. ROSENDALE, and J. A. HARE,2015. Gastric evacuation rates in male Clearnose Skate (Leucoraja eglanteria) in the laboratory. J. Northw. Atl. Fish. Sci., 47: 29-36. doi:10.2960/J.v47.m700

\begin{abstract}
Evacuation rates were determined for Clearnose Skate (Leucoraja eglanteria), an important predator in the mid-Atlantic United States shelf ecosystem. Male Skates (570-730 $\mathrm{mm}$ total length) were fed Sand Lance Ammodytes sp. and allowed to digest from 2-48 hr at two different temperatures. At selected times, fish were removed from tanks, sedated with tricaine methanesulfonate, and subjected to gastric lavage. This procedure was successful at removing the food from the stomachs without injury to the fish. Evacuation rates for the two temperature treatments were fit best by exponential models. The evacuation rates, per hour, were faster at $20^{\circ} \mathrm{C}$ than at $15^{\circ} \mathrm{C}$, resulting in empty stomachs by $24 \mathrm{hr}$ at $20^{\circ} \mathrm{C}$, and $48 \mathrm{hr}$ at $15^{\circ} \mathrm{C}$. Evacuation rates at these temperatures were estimated as 0.102 and 0.059 proportion stomach contents per hour at $20^{\circ} \mathrm{C}$ and $15^{\circ} \mathrm{C}$. These evacuation rates and their temperature dependence are similar to that of other species of elasmobranchs and some teleosts. Evacuation rates are often combined with stomach content data to estimate consumption. The results of this study indicate that evacuation rates by some skates may be up to five times higher than currently used in multi-species and ecosystem models of the Northeast U.S. Shelf. The implication is that consumption may also be higher, highlighting the need for more research to increase the accuracy in evacuation rates estimates.
\end{abstract}

Keywords: digestion, evacuation, consumption, multispecies modeling, ecosystem modeling, elasmobranchs, skates

\section{Introduction}

The importance of skates in the trophic dynamics of the Northeast U.S. Shelf Ecosystem has been changing. Initially, Link et al. (2002) reported that predation by elasmobranchs (1973-1998) had little effect on groundfish numbers or biomass. However, there has been a biomass shift from groundfish to elasmobranchs and crustaceans during the last two decades (Lucey and Nye, 2010), that indicates skates are now among the dominant predators in the shelf ecosystem (Link and Sosebee, 2008; Smith and Link, 2010). Seven species of the family Rajidae are common in the Northeast U.S. continental shelf ecosystem, occupying a variety of depths and temperature ranges (Gabriel, 1992). Clearnose Skates (Leucoraja eglanteria) are among the top 50 demersal species by biomass caught on the Northeast Fisheries Science Center (NEFSC) spring and autumn bottom trawl surveys (Lucey and Nye, 2010) but are more common summer residents south of Cape Cod, Massachusetts and are frequently caught in Mid-Atlantic coastal bays (Wilk et al., 1998; Packer et al., 2003). Large Clearnose Skates $(>61 \mathrm{~cm}$; sexes 
combined), consume approximately equal proportions of benthic invertebrates, various benthic fishes, and Loligo squid (Packer et al., 2003; Link and Sosebee, 2008; Smith and Link, 2010). In some areas of the Mid-Atlantic, the proportion of teleosts in the diets of Clearnose Skates approaches 50\% (Woodland et al., 2011).

To evaluate the importance of Clearnose Skates as predators in the ecosystem, estimates of biomass and consumption rate are needed (see Elliott and Persson, 1978, Durbin et al. 1983). Estimates of biomass can be derived from the Northeast Fisheries Science Center bottom trawl survey. Consumption can be estimated from stomach content data and knowledge of the rate at which food passes into the intestine (termed evacuation rate, Bromley, 1994). There is a relatively large amount of stomach contents data from fish in the Northeast U.S. Shelf Ecosystem (Smith and Link, 2010). Food habit information and consumption rates are used in multispecies models and stock assessments to more accurately predict interactions between species such as groundfish and elasmobranchs. Currently, consumption rates are estimated based on information known for other species or regions (Overholtz and Link, 2007) and there is relatively little system-specific information on how rapidly the food is evacuated, or how evacuation rate is affected by temperature. Rate of evacuation and the shape of the evacuation function depend on various factors including temperature, the fish's metabolism, meal size, and the prey's structure, such as soft tissue, exoskeleton, or bone (Fänge and Grove, 1979; Bromley, 1994; Nelson and Ross, 1995).

Our main objective was to determine the evacuation rates of Clearnose Skate, from the Mid-Atlantic region, under controlled laboratory conditions. To measure evacuation rates, we used gastric lavage, which allows one to determine the proportion of stomach contents remaining without sacrificing the fish (Kamler and Pope, 2001; Waters et al., 2004; Wanner, 2006). We believe this information, along with that already determined for Little Skate and Winter Skate (Nelson and Ross, 1995; Wunder, 1995), will help provide more accurate consumption information for skates in general and that this information will help improve stock assessments and multispecies models in the region.

\section{Materials and Methods}

Clearnose Skates (570-730 mm total length, 935-1650 g) were collected by otter trawl on three fishing trips $5-10 \mathrm{~km}$ off the coast of New Jersey in the last half of August 2013. Water temperature at the nearby Ambrose Buoy averaged $22.3^{\circ} \mathrm{C}$ over the period of collection (National Climatic
Data Center, NOAA). Tow times were $<5$ minutes, and the captured skates were held in an onboard live-well that received regular changes of seawater. Upon arrival at the dock, the skates were transferred to 64 gallon coolers and transported to the laboratory within 20 minutes. Only male Clearnose Skates were captured.

In the laboratory, skates were maintained in holding tanks (2.5 m diameter; $0.5 \mathrm{~m}$ depth) without sediment that received flow-through water from Sandy Hook Bay (salinity $25-26 \mathrm{psu}$, temperature $20-21^{\circ} \mathrm{C}$ ). The light cycle was maintained at a constant $12 \mathrm{hr}$ light and $12 \mathrm{hr}$ dark. Skates are commonly collected from the Hudson-Raritan estuary at these temperatures and salinities during the late summer (Packer et al., 2003). Before experiments commenced, all tanks were gradually decreased in temperature to $20^{\circ} \mathrm{C} \pm 1.0^{\circ} \mathrm{C}$, using a mixture of ambient estuarine water and additions of chilled or heated estuarine water. When experiments at $20^{\circ} \mathrm{C}$ were completed, all tanks including the holding tanks were gradually decreased to $15^{\circ} \mathrm{C}$. Fish were fed a maintenance ration every other day of thawed Sand Lance (Ammodytes sp.) or Silverside (Menidia sp.) ad libitum. Most skates responded immediately to the presence of food, actively searched the bottom, and consumed the Sand Lances whole. Only fish that ate consistently and showed no external abrasions or injuries were used in experiments. The total number of skates used in experiments was 27.

For each evacuation experiment, eight skates at a time were measured, weighed, tagged, and transferred to individual $1.8 \mathrm{~m}$ diameter round tanks. In the first series of experiments, all tanks were maintained at $20^{\circ} \mathrm{C}\left( \pm 1.0^{\circ} \mathrm{C}\right)$, and in the second series, $15^{\circ} \mathrm{C}\left( \pm 1.0^{\circ} \mathrm{C}\right)$. Fish were allowed to reacclimate for one to two days after transfer, and were starved one to two days before each trial. Each skate was then offered four weighed whole Sand Lance, and if those were consumed, another four were weighed and offered. Skates were allowed to feed for $30 \mathrm{~min}$, and then uneaten food was removed, weighed, and subtracted from the amount given. Skates that fed were randomly selected for gastric lavage at different digestion times.

Clearnose Skates that consumed one or more Sand Lances were used for pulsed gastric lavage (Kamler and Pope, 2001). Individual skates were sedated in a cooler containing 201 of water from their own tanks and $1 \mathrm{~g}$ tricaine methanesulfonate. A skate was considered sedated when it could not right itself after being turned over, yet continued to respire. The skate was then removed from the cooler by hand and held ventral side up above a tray, while a hand-pumped compression sprayer nozzle was inserted through the esophagus and into the stomach. A stream of seawater from the sprayer reservoir was gently 
and intermittently pumped into the stomach, lavaging the contents out of the stomach. Lavage was stopped when no more visible material from the stomach was seen and the water expelled was clear. The skate was then returned to its tank and allowed to rest for a minimum of two days. Skates that did not eat in the experimental tanks were removed and replaced with other skates from the holding tanks. Skates that did feed were only subjected to four lavages before they were removed from the experimental tanks and returned to the holding tanks. A few skates were dissected after lavage to confirm the efficiency of the procedure.

The evacuate was sieved through $1 \mathrm{~mm}$ mesh, drained, scraped onto a damp paper towel, and then weighed (wet weight). Mucous, a product of the digestive system, significantly delayed drainage but error was no more than $0.5 \mathrm{~g}$ per stomach, determined by comparison of the weight of an empty wet sieve to the weight of a sieve scraped free of as much mucous as possible.

Evacuation rate, expressed as proportion lost from the stomach per hour, was estimated by statistically modeling percent weight of prey remaining in the stomach by time. Proportion remaining $\left(W_{\mathrm{p}}\right)$ was calculated by dividing the stomach content weight at the time of sampling $\left(W_{\mathrm{t}}\right)$ by the total weight of prey presented to each individual. Evacuation rate was then estimated as the loss of proportion stomach weight over time. Many authors conclude that models of evacuation rate with an exponential curve are most apt for carnivorous teleosts, and that linear or square root models are best for elasmobranchs, depending upon prey type (Fänge and Grove, 1979; Durbin et al., 1983; Nelson and Ross, 1995). Owing to this uncertainty, we fit both a linear (1) and an exponential (2) model.

$$
\begin{gathered}
W_{P}=W_{0}-R t(1) \\
W_{P}=W_{0} e^{-R t}(2)
\end{gathered}
$$

where $W_{\mathrm{p}}$ is the proportion remaining, $t$ is the time of sampling, $W_{0}$ is an estimated parameter of the proportion of the meal that enters the stomach, and $R$ is an estimated parameter of the evacuation rate per hour. $W_{0}$ is often less than $100 \%$ owing to the initial expression of liquid from the prey (Olson and Boggs, 1978).

Bromley $(1988,1994)$ suggested that exponential models of proportion stomach content data are misleading and that evacuation in most species is actually linear. At later hours of digestion, some stomachs with zero contents are found; because proportion stomach content cannot be less than zero these data are in effect censored. To evaluate this assertion we fit equation 1 using linear least square ( $\mathrm{lm}$ function in $R$ ) and equation 2 using several statistical fitting procedures: non-linear least squares (nls function in $R$ ), $\ln$ transformed linear least squares (lm function in $R$ ), a general linear model with Gamma distribution and log link (using the glm function in $R$ ), and a beta regression with a log link (using the betareg function in R) (R CoreTeam, 2014; Cribari-Neto and Zeileis, 2014). These statistical techniques offer a modern approach to that used by Bromley (1988). Models were compared using AIC and $r^{2}$, but direct comparison of all the models was not possible because of the different transformations and estimation procedures. To avoid errors with logtransforming observations of 0 stomach contents at specific times, it was assumed that 0.01 of the original contents remained.

Evacuation rate decreases with decreasing temperature (Durbin et al., 1983) following an exponential model,

$$
R=a e^{b T}(3)
$$

where $a$ and $b$ are parameters of the exponential model, $T$ is temperature, and $R$ is evacuation rate. This model was fit using the two estimates of evacuation rate at the two temperatures. We recognize that this model was fit with two data points only. Our purpose is simply to estimate the parameters $\mathrm{a}$ and $\mathrm{b}$ and compare these parameters to other studies that have estimated evacuation rates in skates.

\section{Results}

During the $20^{\circ} \mathrm{C}$ experiments, gastric lavage was performed 47 times. Randomly selected skates were lavaged at 2, 4, 5 , 6, 8, 9, 12, 20 and 24 hrs (Fig. 1A). Skates were observed to eat from 1 to 11 Sand lances during $30 \mathrm{~min}$. Meal sizes ranged from 2.4 to $51.8 \mathrm{~g}$ (mean $23.0 \mathrm{~g}$ ) averaging $1.73 \%$ of body weight, $(0.20 \%$ to $3.2 \%)$. Evacuation of the stomachs of Clearnose Skates, or the presence of $<5 \%$ of the food given, was complete by $24 \mathrm{hr}$ at $20^{\circ} \mathrm{C}$ (Fig. 1A).

During the $15^{\circ} \mathrm{C}$ experiments, gastric lavage was performed 28 times. Randomly selected skates were lavaged at 4, 5, 20, 24, 28, and $48 \mathrm{hrs}$ (Fig. 1B). Skates were observed to eat only from one to seven Sand lances during $30 \mathrm{~min}$. Meal sizes ranged from 4.7 to $34.8 \mathrm{~g}$ (mean $19.2 \mathrm{~g}$ ) averaging $1.39 \%$ of body weight $(0.39 \%$ to $3.81 \%)(n=28)$. Complete evacuation of the stomachs, or the presence of $<5 \%$ of the food given, occurred by $48 \mathrm{hr}$ at $15^{\circ} \mathrm{C}$ (Fig. 1B). After the lavage procedures, the skates recovered from sedation within 10 or 15 minutes. No observable negative effects were seen from lavage or sedation.

The exponential model (Eq. 2) fit the data better than the linear model (Eq. 1) comparing both AIC and $r^{2}$ values (Table 1). The various approaches to fit the exponential model all yielded similar results (Table 1, Fig. 2). Based 


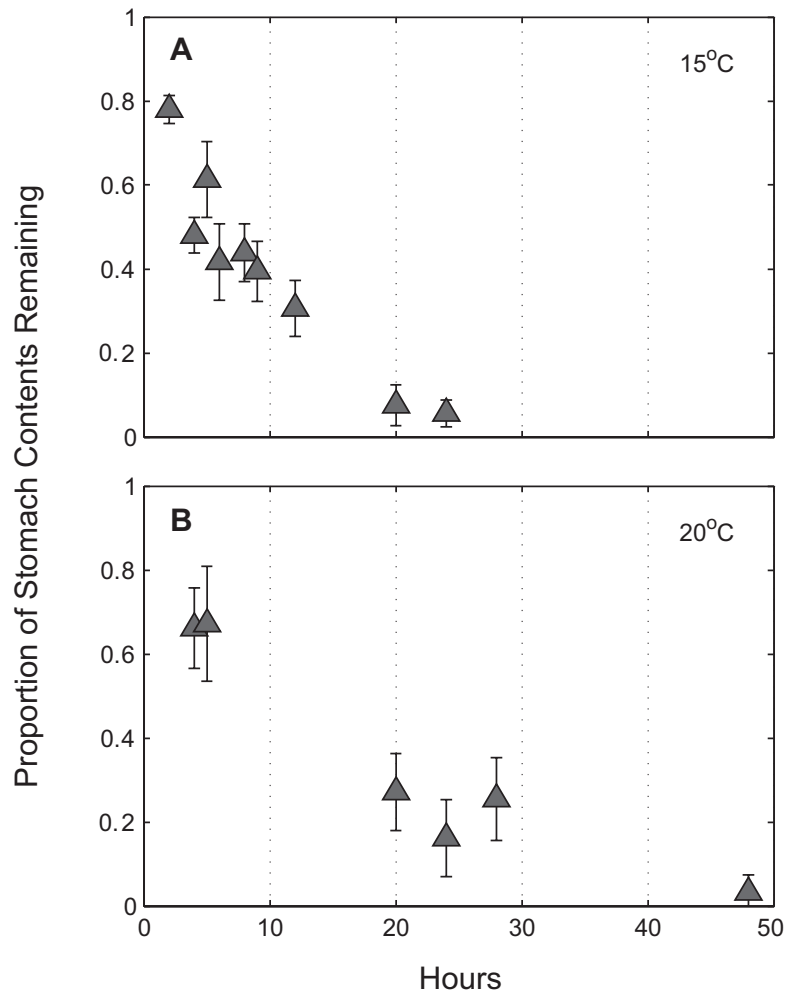

Fig. 1. Mean percent ( \pm 1 standard error) of food digested by hour in Clearnose Skate, Leucoraja eglanteria, at A) $20^{\circ} \mathrm{C}$ and B) $15^{\circ} \mathrm{C}$. on the nonlinear fit of the exponential model, gastric evacuation rates were 0.102 at $20^{\circ} \mathrm{C}$ and 0.059 at $15^{\circ} \mathrm{C}$. The estimates of evacuation rates in this study are comparable with estimates made for other Leucoraja species (Table 2 and Fig. 3).

The model of temperature dependence $\left(R=a e^{b T}\right)$ estimated $a=0.011$ and $b=0.109$ (Fig. 4). These parameters should be viewed cautiously as only two temperatures were used in their estimation. However, the $b$ term of the temperature dependence model was comparable to estimates for teleosts: Elliott (1972) estimated $b=0.112$ and Durbin et al. (1983) estimated $b=0.111$ (Fig. 4). The $a$ term for Clearnose Skates was lower than that for teleosts: Elliott (1972) estimated $a=0.053$ and Durbin et al. (1983) estimated $a=0.041$. These functions we determined are higher than what is used in many regional multispecies models (e.g. Link and Sosebee, 2008) and suggest some phylogenetic concurrence in evacuation rate among skates (Fig. 4).

\section{Discussion}

We found that gastric lavage works well in Clearnose Skates and they are very good laboratory animals. Skates have simple stomachs with an open esophagus and a sphincter at the posterior end, so lavage efficiently washes out the stomach's contents. Wunder (1995) also found that

Table 1. Clearnose Skate, Leucoraja eglanteria: Linear and exponential models, Akaike's Information Criterion (AIC) values, and parameter estimates for the best fit models of evacuation rate in the laboratory. $W_{0}$ is the y intercept, $R$ is evacuation rate, and SE is standard error. Parameter estimates are provided for the best fit model only. $N$ for $20^{\circ} \mathrm{C}$ was 47 , and for $15^{\circ} \mathrm{C}, 28$.

\begin{tabular}{|c|c|c|c|c|c|c|c|}
\hline Temp. & Model & $r^{2}$ & AIC & & $V_{0}$ & & $\mathrm{R}$ \\
\hline & & & & Estimate & SE & Estimate & SE \\
\hline $20^{\circ} \mathrm{C}$ & Linear (Eq. 1) & 0.69 & -42.6 & 0.698 & 0.036 & -0.029 & 0.003 \\
\hline $20^{\circ} \mathrm{C}$ & $\begin{array}{l}\text { Exponential (Eq. 2; } \\
\text { non-linear fit) }\end{array}$ & & -49.7 & 0.909 & 6.191 & -0.102 & 0.011 \\
\hline $20^{\circ} \mathrm{C}$ & $\begin{array}{l}\text { Exponential (log } \\
\text { transformed; linear fit) }\end{array}$ & 0.75 & & 1.263 & 0.181 & -0.164 & 0.014 \\
\hline $20^{\circ} \mathrm{C}$ & $\begin{array}{l}\text { GLM (Gamma } \\
\text { Distribution, link=log) }\end{array}$ & & & 1.029 & 0.178 & -0.119 & 0.014 \\
\hline $20^{\circ} \mathrm{C}$ & Beta $($ link $=\log )$ & 0.75 & & 0.933 & 0.068 & -0.109 & 0.011 \\
\hline $15^{\circ} \mathrm{C}$ & Linear (Eq. 1) & 0.75 & -32.9 & 0.634 & 0.045 & -0.014 & 0.002 \\
\hline $15^{\circ} \mathrm{C}$ & $\begin{array}{l}\text { Exponential (Eq. 2; } \\
\text { non-linear fit) }\end{array}$ & & -49.8 & 0.860 & 0.059 & -0.059 & 0.006 \\
\hline $15^{\circ} \mathrm{C}$ & $\begin{array}{l}\text { Exponential (log } \\
\text { transformed) }\end{array}$ & 0.77 & & 1.124 & 0.253 & -0.081 & 0.009 \\
\hline $15^{\circ} \mathrm{C}$ & GLM (link=log) & & & 1.007 & 0.239 & -0.067 & 0.008 \\
\hline $15^{\circ} \mathrm{C}$ & Beta $($ link $=\log )$ & 0.78 & & 0.866 & 0.075 & -0.060 & 0.006 \\
\hline
\end{tabular}



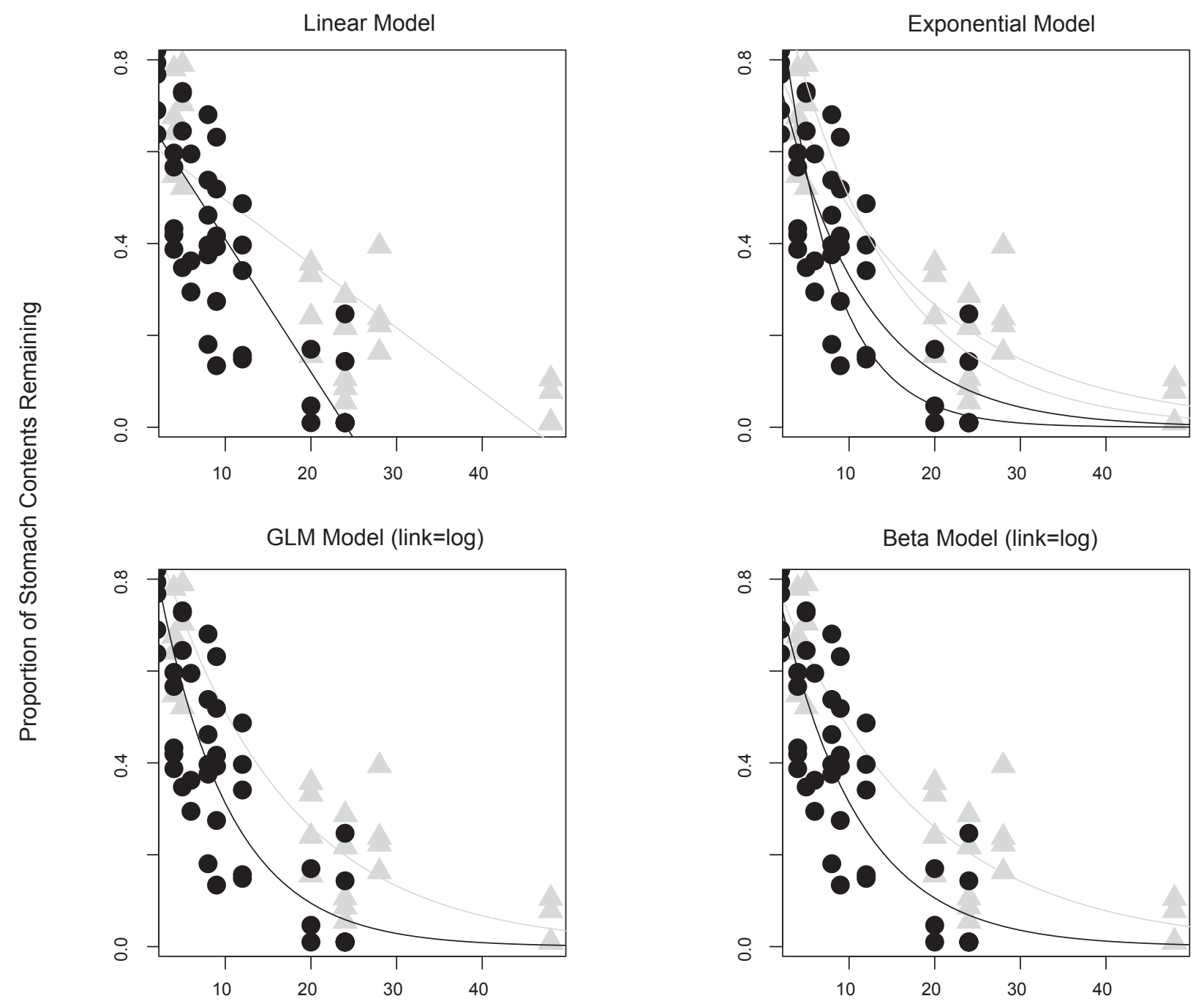

Hours

Fig. 2. Clearnose Skate, Leucoraja eglanteria: Estimated functions using different methods to fit proportion of stomach contents remaining over time, at $20^{\circ} \mathrm{C}$ (black filled circles) and $15^{\circ} \mathrm{C}$ (gray filled triangles).

gastric lavage was very effective on Winter Skates with piscine or crustacean prey.

Bromley (1988, 1994) concluded that exponential evacuation rate models could be misleading and that evacuation in most species of fish is actually linear. Our evaluation of the linear model did not support Bromley's (1988) assertion. However, there are a number of modern statistical approaches that allow non-normal data distributions to be modeled. The Gamma distribution assumes values are positive ( 0 to $\infty)$ and the Beta distribution assumes values ranged between 0 and 1 . A statistical evaluation of the different methods is beyond the scope of this paper, but all the approaches for fitting the exponential model yielded similar results and fit the data better than the linear model.

Evacuation rates derived here for Clearnose Skate are similar to those estimated for other Leucoraja skates when the exponential models are compared. Skates of the genus Leucoraja have similar body shapes, food search behaviors, and possibly comparable activity levels and metabolic rates. When fed small fish, all three species studied to date (Little Skate, Nelson and Ross, 1995; Winter Skate, Wunder, 1995; Clearnose Skate, this study), exhibited rapid commencement of digestion and some variability in rates of digestion among individuals. Although Nelson and Ross (1995) found the best fit for 
Table 2. Comparison of evacuation rates of Clearnose (Leucoraja eglanteria), Little (L. erinacea), and Winter Skate (L. ocellata), number of runs $(n)$, length range, temperature, and prey, reporting the exponential models of evacuation rate from each study for consistency.

\begin{tabular}{lcrrccc}
\hline \hline Species & $n$ & Length $(\mathrm{cm})$ & Temp. & Prey & $\begin{array}{c}\text { Evacuation rate (R. } \\
\text { exponential model) }\end{array}$ & Study \\
\hline Clearnose Skate & 47 & $57-73 \mathrm{~cm}$ & $20^{\circ} \mathrm{C}$ & whole Sand Lance & 0.102 & Stehlik et al. (this study) \\
Clearnose Skate & 28 & $57-73 \mathrm{~cm}$ & $15^{\circ} \mathrm{C}$ & whole Sand Lance & 0.059 & Stehlik et al. (this study) \\
Little Skate & 17 & $33-51 \mathrm{~cm}$ & $10^{\circ} \mathrm{C}$ & whole Sand Lance & 0.056 & Nelson and Ross (1995) \\
Winter Skate & 28 & $40-100 \mathrm{~cm}$ & $10^{\circ} \mathrm{C}$ & 1 Sand Lance & 0.057 & Wunder (1995) \\
Winter Skate & 35 & $40-100 \mathrm{~cm}$ & $10^{\circ} \mathrm{C}$ & 2 Sand Lance & 0.056 & Wunder (1995) \\
Winter Skate & 27 & $40-100 \mathrm{~cm}$ & $10^{\circ} \mathrm{C}$ & 3 Sand Lance & 0.046 & Wunder (1995) \\
Winter Skate & 27 & $40-100 \mathrm{~cm}$ & $14^{\circ} \mathrm{C}$ & 2 Sand Lance & 0.071 & Wunder (1995) \\
\hline
\end{tabular}

evacuation of Sand Lance at $10^{\circ}$ by Little Skate was the square root model, in our study, the exponential model best described the evacuation rates in Clearnose Skates at both temperatures. Studies with Winter Skate indicate that crustaceans may be evacuated more slowly than fish (Wunder, 1995) and this result is also found in other studies (see Durbin et al., 1983). Curvilinear functions better described the evacuation of shrimp by Winter Skate due to a delay in commencement of digestion (Wunder, 1995). Age of the fish, stage of sexual development, mode of ingestion, and structure of the prey also contribute to rapidity of digestion. In this experiment, we reduced variability in evacuation rates from confounding factors by using only one food type and only male skates above a minimum size.

Temperature had a significant effect on evacuation in Clearnose Skate; the evacuation rate was higher at $20^{\circ} \mathrm{C}$ than $15^{\circ} \mathrm{C}$. Temperature has a major influence upon digestion rates due to its effects on biochemical reactions, and evacuation rates increase as temperature increases (Durbin et al., 1983). When temperature was increased, evacuation rate also increased in other skates (Nelson and Ross, 1995; Wunder, 1995). Comparing among the three skate species studied to date indicate a similar temperature dependence in evacuation, but a greater number of species will need to be studied to verify interspecific similarities and differences.

The impact of consumption by elasmobranchs upon prey species in the Northeast U.S. Shelf Ecosystem may be substantial. Estimates for total consumptive demand by Clearnose Skate ranged between 2000 and 18000 $\mathrm{mt} /$ year during the 2000s (Link and Sosebee, 2008). Clearnose Skate is among the top 50 species caught in NEFSC bottom trawl surveys from 1968-2006, though less in biomass than Winter (Leucoraja ocellata), Little (L. erinacea), and Thorny Skates (Amblyraja radiata) (Lucey and Nye, 2010). The seven northeast U.S. skate species currently are managed together as a complex, but because each species has a particular thermal range and life history (Hogan et al., 2013), they may be managed separately in the future. Clearnose Skates are unique in that they are a warmer-water species and more abundant in the Mid-Atlantic Bight (Woodland et al., 2011).

Skate consumptive removals are a means to add ecological considerations to stock assessments and multi-species food web models (Link and Sosebee, 2008). Results

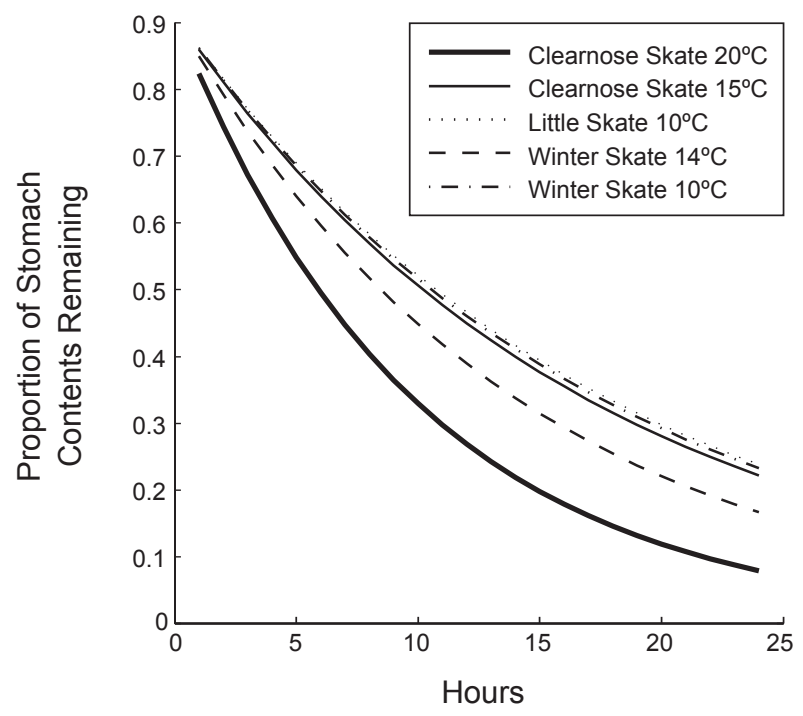

Fig. 3. Evacuation rates (R) of Leucoraja skates consuming small fish at various temperatures (Little Skate, Nelson and Ross, 1995; Winter Skate, Wunder, 1995). 


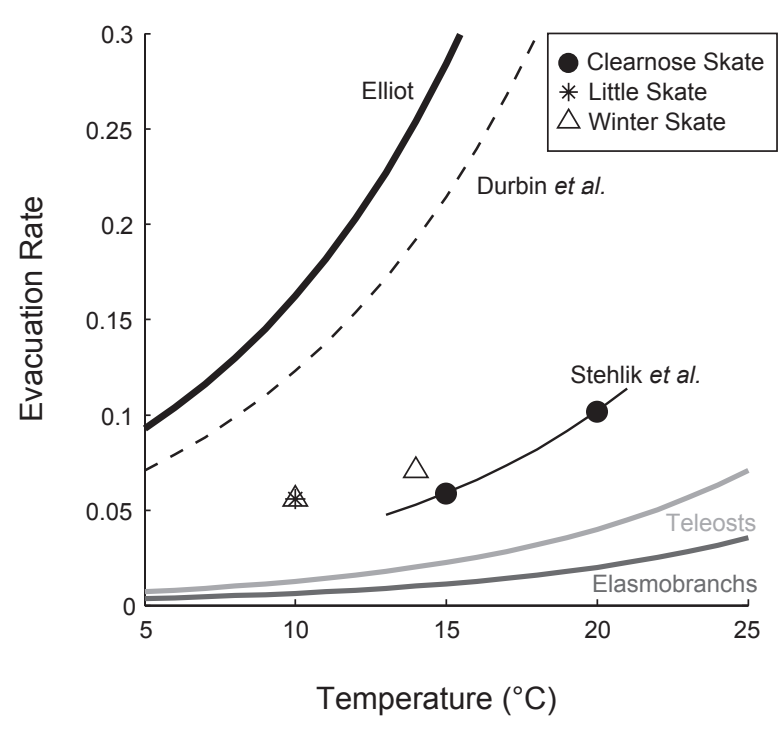

Fig. 4. Comparison of temperature-dependent evacuation rate for Clearnose Skate (this study, black line) and estimates from two other skate species: Little Skate (Nelson and Ross, 1995), Winter Skate (Wunder, 1995). Also shown are two earlier temperature-dependent functions: Atlantic Cod (dotted black line, Durbin et al., 1983) and Brown Trout (Elliott, 1972) (thick black line). The slopes among Clearnose Skate $(b=0.109)$, Brown Trout $(b=0.112)$, and Atlantic Cod $(b=0.111)$ are also very similar, the y-intercepts however are different: Clearnose Skate $(a=0.011)$, Brown Trout $(a=0.053)$ and Atlantic Cod $(a=$ 0.041). The sub-class evacuation rate functions used in many of the multispecies models in the region are also shown: teleost (light gray line) and elasmobranch (dark gray line).

of this study for Clearnose Skate and those of Little and Winter Skate can be used to develop a general evacuation rate function for skates or to reestimate overall consumption by skates in the ecosystem. Consumption is typically estimated as a function of mean stomach content weight and evacuation rate (Durbin et al., 1983). In the Northeast U.S. Shelf Ecosystem, decades of field work have been conducted to quantify stomach contents in multiple species (Smith and Link, 2010), yet relatively few estimates of evacuation rate have been generated (Fig. 4). A greater emphasis should be given to estimating evacuation rates for additional species with an evaluation of Order or Family-level concurrence in evacuation rates. Further, a review of evacuation rates is also warranted. Newly measured evacuation rates and a synthesis of past work could be used to improve upon the sub-class-level estimates typically used in multispecies models in the region (Overholtz and Link, 2007; Link et al., 2008).

\section{Acknowledgments}

We thank John Manderson, Jeffrey Pessutti, Pete Plantamura, and other personnel of the NOAA James J. Howard Marine Sciences Laboratory, and Mike Fogarty and Brian Smith of the Food Web Dynamics Program at the Woods Hole Laboratory. Thanks also to reviewers who suggested improvements to the manuscript.

\section{References}

BROMLEY. P. J. 1988. Gastric digestion and evacuation in whiting, Merlangius merlangus (L.). J. Fish Biol., 33 : 331-338. doi.org/10.1111/j.1095-8649.1988.tb05475.x

1994. The role of gastric evacuation experiments in quantifying the feeding rates of predatory fish. Rev. Fish Biol. Fish., 4: 36-66. doi.org/10.1007/BF00043260

CRIBARI-NETO, F, and A. ZEILEIS. 2010. Beta Regression in R. Journal of Statistical Software: 34 (2), 1-24. http:// www.jstatsoft.org/v34/i02

DURBIN, E. G., A. G. DURBIN, R. W. LANGTON, and R. E. BOWMAN. 1983. Stomach contents of silver hake, Merluccius bilinearis, and Atlantic cod, Gadus morhua, and estimation of their daily rations. Fish. Bull., 81 (3): 437-454.

ELLIOTT, J. M. 1972. Rates of gastric evacuation in brown trout, Salmo trutta L. Freshw. Bio., 2: 1-18. doi. org/10.1111/j.1365-2427.1972.tb01575.x

ELLIOTT, J. M., and L. PERSSON. 1978. The estimation of daily rates of food consumption for fish. J. Anim. Ecol., 47: 977-991. doi.org/10.2307/3682

FÄNGE, R., and D. GROVE. 1979. Digestion, In: Fish Physiology, Vol. 6. W. S. Hoar, D. J. Randall, and J. R. Brett, (eds.), p. 161-260.

GABRIEL, W. L. 1992. Persistence of demersal fish assemblages between Cape Hatteras and Nova Scotia, northwest Atlantic. J. Northwest Atl. Fish. Sci., 14: 29-46. doi. org/10.2960/J.v14.a2

HOGAN, F., S. CADRIN, and A. HAYGOOD. 2013. Fishery management complexes: an impediment or aid to sustainable harvest? A discussion based on the northeast skate complex. N. Am. J. Fish. Manage., 33 (2): 406-421. doi.org/10.1080/02755947.2013.763873

KAMLER, J. F., and K. L. POPE. 2001. Nonlethal methods of examining fish stomach contents. Rev. Fish. Sci., 9: 1-11. doi.org/10.1080/20016491101663

LINK, J. S., L. P. GARRISON, and F. P. ALMEIDA. 2002. Ecological interactions between elasmobranchs and groundfish species on the northeastern US continental shelf. I. Evaluating predation. N. Am. J. Fish. Manage., 22: 550-562. doi.org/10.1577/1548-8675(2002)022<0550:EI $\mathrm{BEAG}>2.0 . \mathrm{CO} ; 2$

LINK, J., W. OVERHOLTZ, J. O'REILLY, J. GREEN, D. DOW, D. PALKA, C. LEGAULT, J. VITALIANO, V. GUIDA, M. FOGARTY, J. BRODZIAK, L. METHRATTA, W. STOCKHAUSEN, L. COL, and C. GRISWOLD. 2008. The northeast U.S. continental shelf Energy Modeling and 
Analysis exercise (EMAX): Ecological network model development and basic ecosystem metrics. J. Mar. Systems, 74 (1-2): 453-474. doi.org/10.1016/j.jmarsys.2008.03.007

LINK, J. S., and K. SOSEBEE. 2008. Estimates and implications of skate consumption in the northeast U.S. continental shelf ecosystem. N. Am. J. Fish. Manage., 28: 649-662. doi. org/10.1577/M07-100.1

LUCEY, S. M., and J. NYE. 2010. Shifting species assemblages in the Northeast US Continental Shelf Large Marine Ecosystem. Mar. Ecol. Prog. Ser., 415: 23-33. doi. org/10.3354/meps08743

NELSON, G. A., and M. R. ROSS. 1995. Gastric evacuation in little skate. J. Fish Biol., 46: 977-986. doi. org/10.1111/j.1095-8649.1995.tb01402.x

OLSON, R. J., and C. H. BOGGS. 1986. Apex predation by yellowfin tuna (Thunnus albacares): independent estimates from gastric evacuation and stomach contents, bioenergetics, and cesium concentrations. Can. J. Fish. Aquat. Sci., 43: 1760-1775. doi.org/10.1139/f86-220

OVERHOLTZ, W. J., AND J. S. LINK. 2007. Consumption impacts by marine mammals, fish, and seabirds on the Gulf of Maine-Georges Bank Atlantic herring (Clupea harengus) complex during 1977-2002. ICES J. Mar. Sci., 64: 83-96.

PACKER, D. B., C. A. ZETLIN, and J. J. VITALIANO. 2003. Essential Fish Habitat Source Document: Clearnose Skate, Raja eglanteria. Life History and Habitat Characteristics. NOAA Technical Memorandum NMFS-NE-174.
RCORETEAM. 2014. R: A language and environment for statistical computing. R Foundation for Statistical Computing, Vienna, Austria. http://www.r-project.org/

SMITH, B., and J. LINK. 2010. The Trophic Dynamics of 50 Finfish and 2 Squid Species on the Northeast US Continental Shelf. NOAA Technical Memorandum NMFS NE 216, 640 p.

WANNER, G. A. 2006. Evaluation of a gastric lavage method on juvenile pallid sturgeon. N. Am. J. Fish. Manage., 26: 587-591. doi.org/10.1577/M05-090.1

WATERS, D. S., T. J. KWAK, J. B. ARNOTT, and W. E. PINE, III. 2004. Evaluation of stomach tubes and gastric lavage for sampling diets from blue catfish and flathead catfish. N. Am. J. Fish. Manage., 24: 258-261. doi.org/10.1577/M02-156

WILK, S. J., R. A. PIKANOWSKI, D. G. MCMILLAN, and E. M. MACHAFFIE. 1998. Seasonal distribution and abundance of 26 species of fish and megainvertebrates collected in the Hudson-Raritan Estuary, January 1992 - December 1997. U. S. Dep. Commer., NOAA, NMFS, Northeast Fish. Sci. Cent. Ref. Doc. 98-10, 145 p.

WOODLAND, R. J., D. H. SECOR, and M. E. WEDGE. 2011. Trophic resource overlap between small elasmobranchs and sympatric teleosts in mid-Atlantic Bight nearshore habitats. Estuaries and Coasts, 34: 391-404. doi.org/10.1007/ s12237-010-9331-0

WUNDER, J. A. 1995. Gastric evacuation in winter skate Raja ocellata. M. Sc. Thesis, University of Rhode Island, Kingston, Rhode Island. 